\title{
MEMÓRIAS DE UM PROFESSOR PRIMÁRIO DA ESCOLA ISOLADA RIO GALO (URUSSANGA-SC/1956 a 1958)
}

\section{MEMORIES OF A PRIMARY SCHOOL TEACHER IN RIO GALO ISOLATED SCHOOL (URUSSANGA-SC) 1956 TO 1958}

\begin{abstract}
Jordana Sartor ${ }^{1}$
Giani Rabelo ${ }^{2}$

\section{RESUMO}

Este artigo apresenta parte da trajetória percorrida pelo professor Celeste Candiotto quando lecionou na Escola de Rio Galo, entre 1956 a 1958, na comunidade de mesmo nome, que pertencia ao município de Urussanga (SC).O objetivo central da pesquisa foi compreender sua escolha pelo magistério, e que lembranças têm de suas práticas pedagógicas. Ele ter ocupado o magistério quando estava em curso a feminização do magistério, chamou a atenção, além deatuar em escola multisseriada. A abordagem desta pesquisa foi qualitativa e como fontes foram utilizados depoimentos do senhor Celeste e documentos cedidos por ele e pela Secretaria Municipal de Educação. Autores como Montenegro (1993), Le Goff (1990) e Bosi (1979) foram usados na discussão sobre memória. Os depoimentos do professor apontam que quebrou tabus, relativo à ideia do castigo escolar, prática comum no tempo em que a escola tradicional tinha fortes traços. Em 1950 já existiam debates que questionavam o castigo escolar, e crianças foram vítimas desta prática. Mas o senhor Celeste apresentou-se revolucionário sendo contra a punir crianças com castigo. Ele também criou nova forma de alfabetizar, por contação de história, algo tão contemporâneo, mesmo tendo o plano de trabalho definido pelo governo estadual para ensinar. $O$ resultado foi positivo, e ele foi convidado a ministrar cursos para professores da região, criando novas oportunidades de conhecimentos sobre o método. A partir deste estudo, é possível conhecer parte da trajetória da escola pública, dando visibilidade aos sujeitos em vezes esquecidos, que fizeram parte dela e contribuíram para sua construção e consolidação.

Palavras Chave: Memória. Magistério. Práticas Pedagógicas.

\section{ABSTRACT:}

This article presents a part of the trajectory followed by Professor Celeste Candiotto when he taught at the Rio Galo School from 1956 to 1958, in the community with the same name that was belonged to Urussanga, SC. The central objective of this research was to comprehend his choose for magisterial and which remembrances have his pedagogical practices. He has occupied the magisterial when were running the feminization of mastership, it shown

\footnotetext{
${ }^{1}$ Acadêmica do Curso de Pedagogia da Unesc. E-mail: jordana-sartor@ hotmail.com.

2 Doutora em Educação pela Universidade Federal do Rio Grande do Sul. Professora titular da Universidade do Extremo Sul Catarinense (UNESC). Atua no Curso de Pedagogia e no Programa de Pós-Graduação em Educação. No PPGE/UNESC ocupa a função de coordenadora adjunta. E-mail:gra@unesc.net.
}

Saberes Pedagógicos, Criciúma, v. 1, nº 1, janeiro/junho 2017.- Curso de Pedagogia- UNESC 
attention, besides of acting in multi serial school. The approach of this research was qualitative and as sources of knowledge, Celeste's documents were investigated, such documents given by him and the Municipal Secretary of Education. Authors like Montenegro (1993), Le Goff (1990) and Bosi (1979) were used on the discussion about memory. The briefs of the professor appoint that he broke taboos related to the idea of scholastic punishment, an usual practice in the time that the traditional school had strong traces. In 1950 there were debates that questioned the scholastic punishment and the kids were victims of it. However, Celeste presented himself as a revolutionary being against punishing them with penalties. He also created a new way of lettering, through storytelling, something in such waycontemporary, even he having the plan of work already ordered by state government to teach. The result went positive and he was invited to minister courses to teachers from the region, creating new opportunities of knowledge about the method. From this study on, it's possible to know a bit of the trajectory of public school, giving visibility to the ones in times forgotten that made their role and contributed for its construction and consolidation.

Key Words: Memory. Magisterial.Pedagogical Practices.

\section{INTRODUÇÃO}

Este artigo apresenta parte da trajetória percorrida pelo professor primário Celeste Candiotto, quando ainda lecionava na Escola Estadual Isolada Rio Galo, entre os anos de 1956 a 1958, localizada na comunidade com o mesmo nome, à época pertencente ao município de Urussanga (SC).

O objetivo central da pesquisa foi de compreender como se deu sua escolha pelo magistério, e que lembranças ele guarda de suas práticas pedagógicas dos primeiros anos de sua experiência na docência em uma escola multisseriada.

A escolha deste tema, em especial deste professor, ocorreu inicialmente pela intenção de reconstruir a história da Escola Estadual Isolada Rio Galo. O referido educandário que hoje já não existe, funcionou na comunidade onde resido até os dias atuais. Em uma das entrevistas para ter mais elementos sobre a existência do estabelecimento de ensino, acabei deparando-me com o senhor Celeste Candiotto. O fato de ter ocupado o magistério em uma época que já estava em curso há bastante tempo a feminização do magistério, chamou muito minha atenção principalmente por atuar em uma escola multisseriada na época.

Ao analisar os educandários multisseriados, Paim (2013, p.95) ressalta: “[...] nas escolas multisseriadas foi marcante para os profissionais que passaram por essas salas de aula repletas de alunos de várias séries." Portanto, esta é característica básica das escolas Saberes Pedagógicos, Criciúma, v. 1, nº1, janeiro/junho 2017.- Curso de Pedagogia- UNESC 
multisseriadas. Já nos anos de 1950 no Brasil, era muito comum encontrar mulheres ocupando os postos no magistério dentro das instituições escolares primárias. Esse processo é denominado por muitos/as historiadores/as da educação de "feminização do magistério." Sobre isso, Almeida (1998, p.01) afirma:

Uma das crenças ilusórias que o imaginário republicano brasileiro entreteceu e que
se estendeu ao século XX foi à fé do liberalismo no poder da escola. Como baluarte
da concretização dessa crença erigiu-se um outro emblema: a destinação
vocacionada feminina para educar a infância. Essa imagética, que se estruturou nos
finais dos oitocentos e persistiu ao longo do século XX, estava voltada
principalmente para um simbolismo atávico ancorado no potencial de redenção pela
pureza e amor ao próximo, atributos dos quais as mulheres eram/são possuidoras, e
teve o efeito de maximizar a importância feminina na educação escolar. Em
contrapartida, enquanto o magistério de crianças se tornou um espaço feminino,
afastou também das salas de aulas os homens que buscaram outras opções na
estrutura hierárquica escolar ocupando cargos administrativos. Vale destacar, a importância desta pesquisa para a historiografia da educação da região do Sul de Santa Catarina, uma vez que estudos relacionados às memórias de professores e professoras que atuaram em escolas multisseriadas, criam possibilidades de reflexões e questionamentos sobre o exercício do magistério, quando o ato de lecionar em escolas isoladas era demasiadamente difícil, frente aos desafios colocados para a escola pública nos anos de 1950 em nossa região e no estado de Santa Catarina.

A partir deste estudo, é possível conhecer um pouco mais a trajetória da escola pública, dando visibilidade aos sujeitos muitas vezes esquecidos, que fizeram parte dela e contribuíram para sua construção e consolidação.

Importante ressaltar o apoio da Secretaria de Educação de Urussanga SC, que disponibilizou as cópias dos documentos da Escola Estadual Isolada Rio Galo.

Entre os trabalhos finais de conclusão defendidos até o momento junto ao curso de Pedagogia da UNESC, não localizei nenhum que abordasse a temática investigada, portanto este é um dado que reforça a relevância do estudo oral proposto.

Um estudo como este, pode nos ajudar a compreender a importância das memórias escolares e do trabalho docente, como a trajetória do professor Celeste Candiotto, que fez seu trabalho acontecer, além disso, nos permite compreender o que seu trabalho 
desenvolvido pode nos revelar, auxiliando-nos no processo de ressignificação no trabalho pedagógico nos dias atuais.

Sobre a memória Montenegro (1993, p. 60) afirma que:

[...] O tempo da memória é o tempo da experiência de um período de vida, de atividade profissional, política, religiosa, cultural, afetiva que nos arrebata e condiciona quase inteiramente, nos fazendo perceber e reconstruir a realidade de uma determinada maneira.

Ainda sobre este tema Le Goff (1990, p. 366) comenta que: “A memória, como propriedade de conservar informações, remete-nos em primeiro lugar a um conjunto de funções psíquicas, graças às quais o homem pode atualizar impressões ou informações passadas, ou que ele representa como passadas."

Nesse sentido, a memória é um diálogo entre o passado e o presente, além disso, os grupos recriam o passado no tempo presente.

Esta pesquisa teve caráter qualitativo, tendo como fonte os documentos oficiais da Escola Estadual Isolada Rio Galo, bem como as memórias do senhor Celeste Candiotto. Como nos traz Gil (2002, p.134): “Já nas pesquisas qualitativas, o conjunto inicial de categorias em geral é reexaminado e modificado sucessivamente, com vista em obter ideais mais abrangentes e significativos."

Além dos documentos cedidos pela Secretaria de Educação de Urussanga- SC, pude contar também com o acervo documental do entrevistado, contendo as portarias das escolas em que trabalhou, certificados dos cursos que realizou ao longo de sua carreira profissional como professor, inclusive seu diploma de Habilitação para o Magistério.

Durante suas aulas, o professor Celeste Candiotto ${ }^{3}$ costumava trazer como mensagem de motivação para seus alunos a seguinte frase: "Sempre trabalhar e estudar para ser um homem amanhã, [...] quando vocês forem adultos, vocês vão usar tudo que a gente está

${ }^{3}$ Celeste Candioto. Entrevista concedida a Jordana Sartor em 12 de Agosto, na cidade de Cocal do Sul (SC) 
ensinando, [...] uma continha de adição é usada todos os dias na vida da gente.” A entrevista realizada com o professor senhor Celeste Candiotto, aconteceu em sua residência na Linha Estação Cocal, na atual cidade de Cocal do Sul-SC, aonde o mesmo reside. A entrevista foi conduzida a partir de um roteiro semiestruturado, gravado com a permissão prévia do entrevistado, acompanhado da assinatura de um Termo de Consentimento. Posteriormente, a entrevista foi transcrita na íntegra e analisada de acordo com o objetivo do estudo.

Sobre este processo de pesquisa amparo-me em Zago (2003, p. 307) quando ela afirma que:

\footnotetext{
Pesquisar é isso. É um itinerário, um caminho que trilhamos e com o qual aprendemos muito, não por acaso, mas por não podermos deixar de colocar em xeque 'nossas verdades' diante das descobertas reveladas, seja pela leitura de autores consagrados, seja pelos nossos informantes, que têm outras formas de marcar suas presenças no mundo. Eles também nos ensinam a olhar o outro, o diferente, com outras lentes e perspectivas. Por isso, não saímos de uma pesquisa do mesmo jeito que entramos porque, como pesquisadores, somos também atores sociais desse processo de elaboração.
}

No presente trabalho, tratarei de reconstruir parte da trajetória percorrida pelo professor primário Celeste Candiotto enquanto educador, referente às práticas educativas por ele realizadas nas instituições de ensino nas quais realizou seus trabalhos, e em especial na Escola Estadual Isolada Rio Galo, que se localizava na época no bairro que tem o mesmo nome, na Cidade de Urussanga- SC, pois na época, Cocal do Sul ainda não havia se emancipado politicamente.

Referente os seus trabalhos realizados nesta instituição de ensino, traremos questões relacionadas às práticas pedagógicas mais utilizadas pelo professor na época na referida escola. E como acontecia o trabalho dele como professor tendo que desempenhar diversos papéis dentro da instituição de ensino, sendo alguns deles: professor, diretor, merendeiro, faxineiro, enfim, tudo que precisasse para manutenção e bom funcionamento da escola. Contudo, traremos à tona uma breve trajetória do professor na instituição de ensino de Rio Galo, destacando também seu trabalho, e conquistas que efetivou nas demais escolas da região do qual atuou.

Outra questão de importante destaque na pesquisa está em compreender como aconteceu a opção pelo magistério. E durante os anos de atuação nas escolas, quais as Saberes Pedagógicos, Criciúma, v. 1, nº1, janeiro/junho 2017.- Curso de Pedagogia- UNESC 
lembranças, conquistas e avanços na educação, efetivados pelo professor em sua trajetória, e os esquecimentos mais marcantes por ele lembrados.

\section{A ESCOLA ESTADUAL ISOLADA RIO GALO NO MUNICIPIO DE URUSSANGA-} SC

Antes de tratarmos sobre a Escola Estadual Isolada Rio Galo, se faz necessário apresentar alguns aspectos do cenário do local onde a escola foi instalada.

Atualmente, a comunidade que leva o mesmo nome da escola, está localizada no município de Cocal do Sul- SC. No entanto, a localidade de Rio Galo pertencia à cidade de Urussanga antes de Cocal do Sul se tornar município.

A cidade de Urussanga tem como data de fundação: 26 de maio de 1878(TOMASI, 2012). De acordo com Vendramini (2003, p. 9) “O nome dado ao município de Urussanga tem origem indígena e atribui-se ao fato de existir na região um pássaro chamado Uru e alguns riachos denominados de Çanga." Na época, o município passou a ser organizado e povoado em meio à chegada dos primeiros imigrantes italianos nesta região. Segundo Tomasi (2012, p.38), a chegada dos colonizadores ocorreu em torno de 1876 a 1878, e estes chegavam de "[...] carros de boi, ou a pé [...].” O responsável pela colônia de Urussanga- SC era o “[...] Engenheiro Joaquim Vieira Ferreira diretor dos Núcleos Coloniais de imigrantes Italianos [...]."

Os estrangeiros recebiam do diretor do núcleo nos primeiros meses da imigração, terrenos que eram pagos também com trabalhos, para desenvolvimento e expansão da cidade (TOMASI, 2012). A cidade de Urussanga acabou se tornando um dos principais centros de colonização italiana do Sul de Santa Catarina. Importante lembrar que antes dos imigrantes italianos chegarem já havia a presença dos índios como os Xoklengnesta região, mas com o processo de colonização acabou por serem exterminados muitos dos índios que ali viviam. As pessoas que eliminavam os índios eram chamadas de "bugreiros" pela prática que realizavam e com isso aos poucos os índios foram sendo extintos de Urussanga e região (TOMASI, 2012). 


\section{SABERES PEDAGÓGICOS}

Revista do Curso de Graduação de Pedagogia - Unesc

Mais tarde, em meados dos anos de 1890, devido ao considerável aumento de sua população “[...] Urussanga se tornou distrito de Tubarão-SC.” (TOMASI, 2012, p.40). "No ano de 1901”, a cidade já é emancipada e muito marcada em sua cultura, pela produção de seus vinhos, sendo que as sementes da uva no início foram trazidas da Itália (TOMASI 2012, p.42).

Já a cidade de Cocal do Sul, município onde está situada a comunidade de Rio Galo atualmente, teve sua emancipação política constituída em 26 de setembro de 1991, tornando-se município. As comunidades que fazem parte de Cocal do Sul são: "Linha Braço Cocal, Linha Ferreira Pontes, Linha Vicentina, Linha Espanhola, Linha Cabral, Rio Perso, Rio Comprudente, Rio Galo, todas localizadas na área rural. Já os bairros da parte Urbana são: Angello Guollo, Boa Vista, Brasília, Centro, Cristo Rei, Guanabara, Horizonte, Jardim Bela Vista, Jardim das Palmeiras, Jardim Elizabeth, Jardim Itália, Monte Carlos, São João, União, Vila Nova, Alphaville, todos localizados na zona urbana da cidade.” (PARÓQUIA NATIVIDADE DE COCAL DO SUL, 2013).

Cocal do Sul é fortemente marcada por suas características culturais, ou seja, as tradições trazidas pelos imigrantes europeus são seguidas até os dias atuais, como por exemplo, na sua produção gastronômica, entre outros do gênero. Outra particularidade do município são os grupos de corais italianos. A localidade também conta com um Museu, contendo um amplo acervo de objetos e materiais deixados pelos colonizadores que aqui se instalaram nos anos de colonização (PREFEITURA MUNICIPAL DE COCAL DO SUL, 1993).

"Apesar de oficialmente a colonização de Cocal, ter-se dado em 1885, já antes desta data, provavelmente em 1880, quando ficou pronta a estrada que ligava o núcleo de Urussanga ao de Cocal, numa extensão de 12 a $13 \mathrm{~km}$, já se instalavam diversas famílias ao longo desta estrada [...]."(PREFEITURA MUNICIPAL DE COCAL DO SUL, 1993, p.2).Mais tarde passou a ser chamado de Rio Cocal, e atualmente de Cocal do Sul. Os meios para se locomover de uma localidade a outra, por exemplo, eram quase todos a pé, pois não havia meios de transportes como carros, somente mais tarde começaram a surgir os primeiros carros de boi, entre outros (PREFEITURA MINICIPAL DE COCAL DO SUL, 1993). 
"O primeiro professor foi Eugênio Rosso, professor de italiano. A educação começou com as $1^{\text {a }} \mathrm{s}$ Escolas Isoladas funcionando de 1888 a 1895.”(PREFEITURA MUNICIPAL DE COCAL DO SUL, 1993, p.10).

A comunidade de Rio Galo conta com uma média de 50 famílias. Há registros de que o nome do bairro se deu pelo fato do local ter se tornado um acampamento de funcionários do Departamento de Estradas de Rodagem de Santa Catarina (DR/SC). Ali os trabalhadores permaneciam acampados nas margens do Rio e conta-se que todos os dias eram acordados pelos cantos de um galo que não se sabia a quem pertencia. "E assim, em uma homenagem a ave que cantava muito alto e sempre nos mesmos horários, a localidade foi apelidada pelos moradores e pelos trabalhadores, e o nome permanece até os dias atuais." (PARÓQUIA NATIVIDADE DE COCAL DO SUL, 2013).

Segundo Virtuoso e Rabelo, (2015, p.71): A primeira escola da comunidade de Rio Galo recebera o nome de "Lorenzo Sacchet e havia cerca de 46 alunos, a escola em 1909 ainda recebia subsídios da Itália, e o valor gerava em torno de 34\$000.”

Poucos são os registros encontrados sobre a educação escolar na localidade de Rio Galo. No Histórico de imigração da Prefeitura municipal de Cocal do Sul, há a indicação de que Paulo Galli lecionou na comunidade em 1922, sendo subsidiado em parte pelo governo italiano (PREFEITURA MUNICIPAL DE COCAL DO SUL, 1993, p.10).

O que se sabe é que a primeira escola inicialmente era étnica italiana, por um bom tempo subsidiada pelo governo da Itália. Mais tarde, em meados dos anos 1950 quando o professor Celeste Candiotto ${ }^{4}$ lecionou na escola, a mesma já era organizada e mantida pelo governo brasileiro, e nem se quer podia-se falar em italiano com as crianças, “[...] nem uma palavra se quer", ressalta o professor.

Como se percebe, foram grandes as transformações na educação no Brasil, em curtos períodos, desde o início das colonizações. Mas é importante ressaltar que a Escola

${ }^{4}$ Celeste Candioto. Entrevista citada. 
Isolada de Rio Galo, na época em que o senhor Celeste trabalhou, ou seja, nos anos de 1956 a 1958, já não era mais étnica, pois já havia sido transferida para a Rede Pública Estadual. Sobre as escolas étnicas italianas, Virtuoso e Rabelo (2015, p. 66) afirmam:

Nesse contexto, marcado fortemente pela presença dos imigrantes italianos e seus descendentes e pela precariedade do ensino público brasileiro, emergiram escolas italianas que se caracterizavam pela forte conotação étnica. Foram criadas e mantidas pelos próprios imigrantes e subsidiadas pelos respectivos países de origem, sendo fechadas definitivamente no início do Estado Novo de Getúlio Vargas, no contexto da Campanha de Nacionalização do Ensino.

Depois da experiência de escola étnica que se tem notícia que funcionou em Rio Galo, o registro que se tem é da instalação da Escola Isolada pública estadual. Quando pensamos em instituições escolares deve-se levar em conta os processos de transformações ocorridas durante todos esses anos e suas influências para os dias atuais, mas, sobretudo a importância do estudo das instituições educativas, para o campo da história da educação. Com relação a isso Sanfelice (2006, p.24) comenta:

\footnotetext{
Mergulhar no interior de uma Instituição Escolar, com o olhar do historiador, é ir em busca das suas origens, do seu desenvolvimento no tempo, das alterações arquitetônicas pelas quais passou, e que não são gratuitas; é ir em busca da identidade dos sujeitos (professores, gestores, alunos, técnicos e outros) que a habitaram, das práticas pedagógicas que ali se realizaram, do mobiliário escolar que se transformou e de muitas outras coisas.
}

Tudo indica que seu funcionamento ocorreu principalmente com o apoio da comunidade. O Registro de Transferência do Imóvel da Comarca de Urussanga- (1975) apresenta que o terreno foi doado por "Quintino Possamai Della e esposa Bracelina Possamai Della, e Egídio Fontanella e esposa Helena Fontanella”. E este foi encontrado na coleta dos dados dos documentos junto a Secretaria de Educação de Urussanga, o terreno só foi transferido oficialmente e registrado em cartório no dia 17 de fevereiro de 1975, na Comarca de Urussanga. Porém, há vestígios de que a escola já funcionava anos antes da transferência oficial do imóvel. Como apresentam registros escolares de turmas multisseriadas que ali já estudaram anos antes da transferência do imóvel, que se deu somente em 1975.

Lamentavelmente, há poucos registros sobre a trajetória da Escola Estadual Isolada Rio Galo, o que se sabe a respeito da mesma, está contido no pequeno acervo junto a 
Secretaria de Educação de Urussanga-SC. Atualmente o prédio escolar não existe mais, por conta de ter sido demolido há anos atrás, em decorrência da não utilização do educandário e para a abertura de uma estrada no local. Isso faz pensar sobre a pouca importância dada ao patrimônio educativo pelo poder público, provavelmente por terem sido consideradas sinal de atraso na educação, como afirma Ferber (2014, p.9):

As escolas isoladas nunca foram um modelo de educação moderna, nem pelo seu método de ensino e muito menos pela sua arquitetura, ao contrário, elas eram um símbolo de "atraso" devido ao seu aspecto físico, pois não tinham a pompa dos prédios escolares destinados apenas aos grupos escolares.

Referente aos documentos da escola, poucos foram guardados pela Secretaria de Educação de Urussanga, os existentes são do ano de 1965 em diante. Dos anos em que o professor e senhor Celeste trabalhou, ou seja, 1956 a 1958 não se encontrou mais nada. É relevante destacar a importância da preservação deste tipo de material, para que se possam analisar as transformações históricas da educação escolar no decorrer dos tempos, o que possibilitaria novos estudos no campo da história da educação, inclusive para compreender as transformações nos processos educativos.

Mesmo diante dos registros legais encontrados, é possível que a escola antiga tenha funcionado antes da década de 1970, porém, como relatou o senhor Celeste Candiotto, não no mesmo local. O referido professor atuou no estabelecimento entre os anos de 1956 a 1958. E é sobre suas memórias e sobre esta experiência, que iremos tratar nos itens que seguem.

\section{CELESTE CANDIOTTO E A OPÇÃO PELO MAGISTÉRIO}

O senhor Celeste Candiotto nasceu no município de Urussanga, em 30 de janeiro de 1939. Filho de Giacomo Candiotto e Catharina Cechinel Candiotto, casou-se com Salute Possamai Della Candiotto que foi uma mulher que também marcou de certo modo a história da região, pois como nos traz o site Portal Cocal (2016, p. 1):

A nova unidade também presta homenagem à primeira enfermeira do município, Salute Possamai Della Candiotto, carinhosamente conhecida como Amábile, in 
memoriam, por toda a dedicação prestada. Agradeço ao prefeito, aos vereadores e toda administração por este tão importante reconhecimento, com certeza ela estaria muito feliz por esse momento. Minha esposa sempre atuou de forma dócil, profissional e pelas pessoas. Ela tinha muito amor pelo que fazia. Em São Paulo quando iniciou, chegava a realizar de 3 a 4 partos ao mesmo tempo. A proteção, ela pedia a Nossa Senhora do Bom Parto. Que a sua história possa servir de inspiração aos profissionais de hoje. Que eles possam seguir este exemplo, de fazer com amor e ajudar o próximo, relatou o professor aposentado, Celeste Candiotto, esposo da homenageada.

Com dona Salute (já falecida), o senhor Celeste casou-se e teve dois filhos, e atualmente um neto. Hoje ele reside na Linha Estação Cocal, que faz parte da cidade de Cocal do Sul, juntamente com sua família.

O senhor Celeste já desde muito jovem apresentava o desejo e o interesse por ensinar e ser professor. Ao ser indagado sobre o "ato de ensinar", ele demonstra muita saudade, e sentimentos de carinho, ainda hoje pela profissão que parece ter marcado profundamente sua vida. Quando questionado a respeito de seu primeiro contato com a profissão, entusiasmado o senhor Celeste ${ }^{5}$ declara: "Chegou aqui em casa algumas crianças e eu comecei a ensinar, e a criança aprendia, aí achei que o caminho era este, então eu comecei a ensinar."

A escolha pelo magistério, sempre foi um sonho almejado pelo senhor Celeste, e quando surgiu a primeira oportunidade de ensinar não pensou duas vezes e teve sua primeira experiência como professor e regente de classe, isso antes mesmo de realizar o Curso de Magistério, concluído só em 11 de dezembro de 1973, na escola preparatória de nome: "Deputado Antonio Guglielmi Sobrinho", na cidade de criciúma.

O senhor Celeste lecionou em várias escolas municipais e estaduais, dentre elas a Escola Estadual Isolada Rio Galo, em (15 de março de 1956) sendo esta sua primeira experiência. Também trabalhou nas escolas: Escola Municipal de Linha Espanhola (23 de setembro de 1981), Escola Reunida "Linda Canela" de Visconde de Taunay (11 de fevereiro de 1959), e Escola Isolada Linha Cabral pertencente a Morro da Fumaça (29 de julho de 1974). Mas segundo o entrevistado, a escola que mais marcou sua vida de educador foi a de

${ }^{5}$ Celeste Candioto. Entrevista citada.

Saberes Pedagógicos, Criciúma, v. 1, nº 1, janeiro/junho 2017.- Curso de Pedagogia- UNESC 
linha Cabral, por ser ali que aperfeiçoou suas práticas pedagógicas, e por ser ali que criará seu novo método de alfabetizar.

O senhor Celeste inicia sua experiência no magistério sem nenhuma formação específica, utilizando-se de seus conhecimentos empíricos, além de novos saberes obtidos a partir de pesquisas que fazia em livros que tinha acesso.

O professor senhor Celeste Candiotto quando criança estudou até a $5^{\circ}$ série no grupo escolar Professor Padre Schuler, que na época ainda se localizava no seu local de origem, onde hoje fica a prefeitura municipal de Cocal do Sul. E mais tarde, fez o curso normal regional, onde terminou sua formação do segundo grau completo e Magistério.

Além de lecionar para turmas de aproximadamente 25 a 30 alunos/as, quando estava em casa, também passava seu tempo ensinando seus filhos em idade de alfabetização, e sobre isso Celeste Candiotto ${ }^{6}$ destaca: "Eu pegava um carvão lá atrás de casa, e ia ensinando meu filho, e ele ia aprendendo."

Entre suas experiências como professor primário na escola de Rio Galo, escola em que ele lecionou por três anos, possui lembranças muito positivas sobre sua relação com a comunidade escolar, descrevendo-a como bastante participativa, sendo que os pais compareciam às reuniões que aconteciam nas dependências da escola, e na sua avaliação eram bastante preocupados com seus filhos e muito colaborativos para o desenvolvimento da escola.

Ao descrever a estrutura do educandário, afirma o senhor Celeste ${ }^{7}$ que quando iniciou seus trabalhos naquela escola, depois de fechar como escola étnica, funcionou em uma pequena casa de madeira por um tempo como escola pública. A casa passou por uma reforma, sendo retiradas suas repartições internas, tornando-se uma grande sala de aula.

Sobre a mobília, ele relata que havia carteiras com assentos para cada dois alunos, além de duas grandes lousas (quadros). Ele lembra que este tipo de mobília era uma singularidade da Escola Estadual Isolada Rio Galo, pois em outras escolas em que trabalhou,

\section{${ }^{6}$ Celeste Candioto. Entrevista citada.}

${ }^{7}$ Celeste Candioto. Entrevista citada.

Saberes Pedagógicos, Criciúma, v. 1, nº1, janeiro/junho 2017.- Curso de Pedagogia- UNESC 
encontrou carteiras com assentos para até quatro alunos, destaca o entrevistado. E a respeito da mobília escolar Castro e Silva (2011, p.211) afirmam:

A estrutura material da escola é um lugar, um espaço peculiar e relevante. É nela também que se educa por suas presenças e ausências. Esta estrutura material e o uso que dela se faz são componentes, nem sempre explicitados, do trabalho educativo.

O senhor Celeste, hoje com seus 77 anos de idade, guardou algumas lembranças de seu tempo de professor da escola primária, e suas narrativas nos auxiliaram a compreender parte da experiência que ele vivenciou. Isso nos faz pensar sobre o que Eclea Bose (1994, p.39) aponta:

\begin{abstract}
A memória é um cabedal infinito do qual só registramos um fragmento. Frequentemente, as mais vivas recordações afloravam depois da entrevista, na hora do cafezinho, na escola, no jardim, ou na despedida do portão. Muitas passagens não foram registradas, foram contadas em confiança, como confidências. Continuando a escutar ouviríamos outro tanto e ainda mais. Lembrança puxa lembrança e seria preciso um escutador infinito.
\end{abstract}

Com este entendimento proposto pela autora é que iremos nos aproximar de suas práticas e saberes desenvolvidos como professor primário, algo emblemático para uma época em que a feminização do magistério já era uma realidade no Estado de Santa Catarina e região, como em todo país.

\title{
4 SABERES E PRÁTICAS DE UM PROFESSOR PRIMÁRIO
}

O professor Celeste Candiotto ${ }^{8}$ descreve seus antigos alunos como sendo sempre muito obedientes e possuidores de grande desejo de aprender. Sobre isto ele relata: "[...] as crianças eram muito obedientes, muito fáceis de trabalhar.”

Nos anos em que o senhor Celeste trabalhou na Escola Estadual Isolada Rio Galo, ele era quem realizava todas as funções, ou seja, professor, diretor, e, além disso, responsável pela merenda. Muitas vezes até trazia a merenda pronta de casa. Na condição de diretor ele recebia as pessoas que chegavam para realizar visitas e assinava os documentos oficiais da escola.

${ }^{8}$ Celeste Candioto. Entrevista citada.

Saberes Pedagógicos, Criciúma, v. 1, nº 1, janeiro/junho 2017.- Curso de Pedagogia- UNESC 
Antes de ele lecionar na referida escola, todo o ensino era em italiano, mas nos anos em que o senhor Celeste efetivou seus trabalhos no prédio escolar ainda de madeira, já era proibido lecionar em italiano, bem como se comunicar com os alunos ou as crianças entre si em língua estrangeira. E referente a isso Nicácio (2008, p.12) relata:

No entanto, é no período Vargas que a construção da identidade nacional atinge características marcantes. O estímulo ao patriotismo, o uso de símbolos nacionais e a comemoração das datas nacionais também são pontos destacados na legislação federal, a questão educacional extrapola os limites da escola para chegar à população adulta através de solenidades públicas de exaltação aos símbolos e heróis nacionais.

Costumava receber também a visita de inspetores na escola, que visitavam o estabelecimento com certa frequência. Segundo o professor, tratava-se de uma autoridade severa, que vinha inspecionar o trabalho pedagógico realizado na escola algumas vezes no ano. Era uma espécie de diretor geral que fiscalizava o uso da língua, entre outras questões. Para Celeste Candiotto": "Se ele chegasse à escola e encontrasse uma criança falando em italiano, o professor era até mesmo suspenso, pois era obrigatório falar a língua em português." Ele lecionava no início de suas experiências como professor em turmas multisseriadas, ou seja, lecionava para uma mesma turma com alunos de $1^{\mathrm{a}}$ a $4^{\mathrm{a}}$ série. Em relação a esta modalidade de ensino, o professor Celeste ${ }^{10}$ destaca que “[...] o professor tinha que estar muito bem preparado." Ou seja, deveria estar com o seu planejamento em dia, pois era grande comprometimento trabalhar com as quatro séries ao mesmo tempo em uma única sala de aula. E sobre esta questão Paim (2013, p.94) destaca: "Como a professora tinha muitos afazeres na escola, para além das aulas, eram necessários uma boa organização e planejamento, pois, os alunos não podiam ser prejudicados pelas outras tarefas realizadas na escola."

No cotidiano da sala de aula, quando algumas crianças alcançavam boas notas, acabavam ajudando nas atividades com os demais alunos da sala que possuíam maiores dificuldades de aprendizado, por exemplo: uma criança do $4^{\circ}$ ano que tivesse alcançado os objetivos das atividades propostas ajudava a outra criança da $1^{\mathrm{a}}$ série.

\section{${ }^{9}$ Celeste Candioto. Entrevista citada.}

${ }^{10}$ Celeste Candioto. Entrevista citada.

Saberes Pedagógicos, Criciúma, v. 1, nº 1, janeiro/junho 2017.- Curso de Pedagogia- UNESC 


\section{SABERES PEDAGÓGICOS}

Revista do Curso de Graduação de Pedagogia - Unesc

Sobre a realização das atividades pedagógicas, o senhor Celeste ${ }^{11}$ destaca durante a entrevista: "Eu comprava vários livros, também na livraria Fátima, que tinha em Criciúma, no meu tempo na escola do Rio Galo no início o governo não mandava nada, era aquele livro que a criança comprava é somente isso." Os alunos também não recebiam nenhum material de apoio, sendo assim também tinham que comprar seu livro para realização das atividades. $\mathrm{O}$ subsídio fornecido pelo governo na época era de extrema precariedade, sendo assim, era a comunidade que colaborava para manutenção e funcionamento das escolas no geral, e a respeito da colaboração fornecida pelo governo o senhor Celeste ${ }^{12}$ acrescenta: "Pouca coisa, era muito precário, mas a comunidade ajudava também.”

Ao analisar sua experiência quando ainda lecionava na Escola Estadual Isolada Rio Galo, senhor Celeste manifesta grande repúdio e indignação quando se remete a forma rigorosa como a educação escolar era concebida, e em suas palavras o professor Celeste ${ }^{13}$ acrescenta que “[...] o rigor daquele tempo que até hoje eu tenho nojo e muito, é que as crianças poderiam tirar nota 10 o ano inteiro, mas havia uma prova final para todos, e se a criança ficasse nervosa na hora da prova e não conseguisse fazer a prova, rodava o ano."

Segundo o senhor Celeste ${ }^{14 ،}$ o exame vinha em envelope lacrado e era elaborado pelo inspetor escolar, passava também pela banca examinadora, que trazia a prova e abria na sala de aula na frente dos alunos." Conta ele que até a folha da prova não era a mesma folha de caderno que as crianças estavam acostumadas a usar no dia a dia durante o ano letivo, a folha da prova era de papel almaço. Os critérios de notas naquele tempo também eram diferentes dos utilizados nos dias de hoje, ou seja, era de peso 10 a 100, lembra o senhor Celeste. Recorda também que haviam avaliações que eram realizadas oralmente com as crianças em sala de aula. Todas estas práticas de ensino eram cotidianas do ensino tradicional na época, e além destas, outras características também marcaram a época como nos traz Aragão e Freitas (2012, p. 25): “A palmatória, o chicote, a vara, as carteiras, os livros, o quadro de giz e outros objetos faziam parte da cultura escolar daquele tempo histórico."

\footnotetext{
${ }^{11}$ Celeste Candioto. Entrevista citada.

${ }^{12}$ Celeste Candioto. Entrevista citada.

${ }^{13}$ Celeste Candioto. Entrevista citada.

${ }^{14}$ Celeste Candioto. Entrevista citada.
} 
Sobre os métodos de alfabetização utilizados conta ele que inicialmente trabalhou com cartilhas, por meio da memorização, ou seja, "decoreba", até que certo dia acabou realizando uma grande descoberta. Sobre isso Celeste Candiotto ${ }^{15}$ lembra: "Durante os anos que trabalhei eu fiz uma descoberta quanto a alfabetização, era de que a criança aprende muito melhor quando o professor conta uma história, a gente inventa uma história.” O que ele fazia era dar vida para as letras do alfabeto em cada história dramatizada, desenhando as letras no quadro, e assim criando possibilidades de conhecimentos aos alunos. Ao trabalhar desta forma, ele inovava utilizando diversos recursos para ensinar, além das histórias contadas fazia a representação das mesmas por meio de desenhos.

Mais tarde o professor senhor Celeste foi convidado a ministrar cursos para outros professores com o tema: “Alfabetizando através de histórias.” Inicialmente o fez em Morro da Fumaça (SC) e depois em Criciúma (SC) no Colégio Normal, em função da Supervisora de Ensino ter adorado seu trabalho.

E quando se refere ao aprendizado das crianças naquele tempo, o senhor Celeste ${ }^{16}$ destaca: "Na escola daquele tempo, a criança tinha que sair da escola ( $4^{\mathrm{a}}$ série) já sabendo as quatro operações e saber ler e a escrever."

Outra questão muito lembrada pelo professor, quando questionado a respeito do trabalho realizado nas instituições em que atuou, mais precisamente na Escola Estadual Isolada Rio Galo, ele comenta que não era trabalhado nada além do apresentado no Programa de Ensino proposto pelo governo à época. As datas comemorativas eram todas relembradas, e dentre elas destacava-se: Descobrimento do Brasil, Sete de Setembro, Natal, Páscoa, Dia dos Pais, Dia das Mães.

A utilização das datas comemorativas no trabalho pedagógico era muito frequente desde os anos em que o professor senhor Celeste lecionou na escola de Rio Galo, como pude observar durante a entrevista feita com o professor, ao lhe questionar a respeito de seu trabalho com datas comemorativas, o senhor Celeste ${ }^{17}$ ressalta: "Sim, todos os anos, descobrimento do Brasil, Sete de Setembro, Natal, Páscoa, Dia das Mães, Dia dos Pais.”

\footnotetext{
${ }^{15}$ Celeste Candioto. Entrevista citada.

${ }^{16}$ Celeste Candioto. Entrevista citada.

${ }^{17}$ Celeste Candioto. Entrevista citada

Saberes Pedagógicos, Criciúma, v. 1, nº 1, janeiro/junho 2017.- Curso de Pedagogia- UNESC
} 
Durante a coleta de dados, junto à Secretaria de Educação de Urussanga, ao examinar os documentos da escola, encontrei um diário escolar da época e nele está registrado: "festas e comemorações cívicas", no qual o professor descrevia todas as atividades referentes as datas comemorativas trabalhadas durante o semestre. Entre as atividades mais trabalhadas estavam: "cartões, versos, cantos, palestras, murais."

Ao se referir às condições de trabalho nas escolas, ele avalia que somente começaram a melhorar um pouco, além de o professor ser mais valorizado, a partir dos anos de 1960. Talvez seu depoimento tenha a ver com a experiência que vivenciou na Escola da Linha Cabral (29 de julho de 1974), pois lá, uma de suas conquistas foi ter conseguido desdobrar a escola, dividindo a turma de $1^{\mathrm{a}}$ a $4^{\mathrm{a}}$ série em dois turnos, ou seja, duas turmas no período da manhã, e duas turmas no período da tarde, exigindo a contratação de outros professores. As aulas iniciavam às $08 \mathrm{~h} 00 \mathrm{~min}$ e terminavam às $12 \mathrm{~h} 00 \mathrm{~min}$ e à tarde era das: $13 \mathrm{~h} 00 \mathrm{~min}$ e terminava as $17 \mathrm{~h} 00 \mathrm{~min}$.

Após concluir o Curso Magistério no ano de 1973, o professor senhor Celeste nunca mais parou de estudar. Buscava constantemente se atualizar em suas práticas de ensino e aprendizagem, realizando cursos de formação continuada sempre que conseguia, pois havia diversas dificuldades para realizar os cursos em função da distância e o difícil acesso. Havia também poucos meios de transporte para tal, por isso tinha que atravessar grandes matas, na maioria das vezes para chegar aos locais dos cursos, relembra o professor.

$\mathrm{Na}$ época, também era muito difícil o acesso a novas tecnologias, sendo que o professor utilizava-se somente do livro e quadro, para criar possibilidades de produção de conhecimento. Ao comparar com os dias de hoje, o senhor Celeste ${ }^{18}$ acredita estarmos em melhores condições. Um exemplo citado é o da disciplina de matemática, uma vez que há o uso da calculadora, diferente daquela época na qual as crianças tinham que saber na forma decorando a resposta dos cálculos propostos pelo professor, tornando-se mais difícil e demorado.

O que mais chamou atenção na trajetória de trabalho e de vida percorrida pelo professor Celeste foi sua visão crítica e inovadora para a época, pois em meados dos anos

${ }^{18}$ Celeste Candioto. Entrevista citada.

Saberes Pedagógicos, Criciúma, v. 1, nº 1, janeiro/junho 2017.- Curso de Pedagogia- UNESC 
1950, quando a prática dos castigos escolares era bastante utilizada na maior parte das escolas da região sul de Santa Catarina, o senhor Celeste argumenta nunca ter aplicado em suas aulas com nenhum de seus alunos. Ao lembrar-se desta questão o professor Celeste ${ }^{19}$ declara: “ $O$ castigo escolar era proibido naquele tempo, desde o meu tempo era tudo proibido.”

Pode-se observar que o senhor Celeste não se utilizou desta prática em nenhum momento de sua vida como professor, mesmo a prática do castigo sendo muito frequente naquela época, onde muitos professores se utilizavam da mesma como forma de punição, e para manter a ordem na sala de aula. Sobre esta questão Aragão e Freitas (2012, p. 18) relatam:

Férulas, chicotes e palmatórias faziam parte dos objetos utilizados pelo professor para educar os alunos, mantendo a ordem e a disciplina. Todavia, tais práticas acabaram por denunciar uma sociedade impregnada de práticas violentas, sendo comuns não apenas no universo escolar, mas em todo o processo que envolvia relações humanas.

Nos dias atuais, o passatempo do senhor Celeste é ensinar seu neto de 11 anos de idade nas tarefas escolares, e afirma fazê-lo com "muito amor", semelhante à dedicação que teve com seus alunos. Ele comenta que se hoje chegassem crianças em sua casa, com o desejo de aprender a ler e a escrever, ele ensinaria do mesmo modo quando lecionou na sua experiência de professor primário.

\section{CONCLUSÃO}

Há indícios de que muito antes de funcionar a Escola Isolada Rio Galo na comunidade que tem o mesmo nome, houve outro estabelecimento de ensino que funcionou como escola étnica, ou seja, as crianças só eram ensinadas em língua italiana.

Poucos documentos restaram sobre a implantação e funcionamento da Escola Isolada Rio do Galo, sendo possível obter alguma informação a partir de alguns documentos e das memórias do professor senhor Celeste Candiotto, que atuou nela entre os anos de 1956 a 1958.

${ }^{19}$ Celeste Candioto. Entrevista citada. 
O referido professor iniciou seu sonho de ser professor, "ensinando algumas crianças que foram até sua casa para aprender a ler e escrever.” Ele deu início aos seus trabalhos na escola pública como professor regente de classe, realizando seus primeiros trabalhos em Escolas Isoladas da época.

Os depoimentos do professor senhor Celeste apontam que ele quebrou tabus relativos à ideia do castigo escolar, prática muito comum em sala de aula, em um momento em que a escola tradicional ainda tinha fortes traços. Apesar de nos anos 1950 já existir um debate que questionava o castigo escolar, muitas crianças foram vítimas desta prática pedagógica. Mesmo neste cenário, o senhor Celeste apresentou-se revolucionário, posicionando-se totalmente contra o ato de punir crianças.

O professor, além disso, criou uma nova forma de alfabetizar, ou seja, por contação de história, algo tão contemporâneo, mesmo tendo um plano de trabalho definido pelo governo estadual para as escolas primárias. O resultado foi extremamente positivo, ao ponto de ele ser convidado a ministrar cursos para professores da região, para criar novas oportunidades de conhecimentos em torno do método que criara.

Outras experiências que ficaram registradas em suas memórias foi $o$ desdobramento de algumas escolas da região que ele realizou, e a sua principal conquista em ter concluído o Magistério.

Os descasos do governo com a educação também marcaram suas memórias, principalmente no que se refere aos baixos investimentos e falta de valorização dos profissionais da educação.

A realização desta pesquisa foi de grande relevância para a história da educação de nossa região, pois nos faz repensar sobre as práticas educativas, práticas estas que foram vivenciados pelo senhor Celeste Candiotto, na busca incessante para a construção de uma educação inovadora, como foi percebida na criação do método de alfabetização implementado por ele. Um elemento que merece destaque é que, mesmo em um cenário demarcado pela presença massiva de mulheres no magistério, o professor senhor Celeste não abandonou em momento algum sua carreira profissional, e a descreve com carinho e orgulho em ter sido professor primário. 


\section{REFERENCIAS}

ALMEIDA, Jane S. de. As Professoras no século XX: as mulheres como educadoras da infância. São Paulo: Editora da UNESP, 1998. Disponível em:

<http://sbhe.org.br/novo/congressos/cbhe3/Documentos/Coord/Eixo3/482.pdf > Acesso em: 08 Out. 2016.

ARAGÃO, Milena; FREITAS, Anamaria Gonçalves Bueno. Práticas de castigos escolares: enlaces históricos entre normas e cotidiano, 2012. Acesso em: 03 Out. 2016.

BOSI, Ecléa. Memória \& sociedade: lembranças de velhos. São Paulo: Companhia das Letras, 1994.

Celeste Candiotto. Entrevista concedida a Jordana Sartor. Cocal do Sul-SC, 12 de Agosto de 2016.

COMARCA DE URUSSANGA-SC. Certidão de registro e transferência do imóvel (17 de fevereiro de 1975, Comarca de Urussanga-SC)

CASTRO, Raquel Xavier de Souza; SILVA, Vera Lucia Gaspar. Cultura material da escola: entram em cena as carteiras. Curitiba: educar em revista, 2011. Disponível em: <http://www.scielo.br/pdf/er/n39/n39a14.pdf > Acesso em: 17 Out. 2016.

FERBER, Luiza Pinheiro; Escolas Isoladas: Um mal necessário (1910-1915): Florianópolis: 2014. Disponível em:

<http://www.encontro2014.sc.anpuh.org/resources/anais/31/1403635023_ARQUIVO_VERS AOenviada.pdf> Acesso em: 17 Out. 2016.

GIL, Antônio Carlos. Como elaborar projetos de pesquisa. 4. Ed. São Paulo: Atlas, 2002.

LE GOFF, Jacques. História e memória. Campinas, SP: UNICAMP, 2003. Acesso em: 25 Out. 2016.

MONTENEGRO, Antônio Carlos. História oral, caminhos e descaminhos. Revista Brasileira de História. São Paulo. v.13,n.25/26. Set.92/ago.93.

NICÁCIO, Jamilly da Cunha. O processo de nacionalização do Brasil. Rio de Janeiro: revista de história contemporânea, 2008. Acesso em: 01 Out. 2016.

PARÓQUIA NATIVIDADE COCAL DO SUL. Disponível em:<www.paroquianatividade.com.br/>. Acesso em: 08 Out. 2016.

PAIM, Elison Antonio. Professoras: narradoras de memórias e experiências do trabalho em escolas multisseriadas em Palmitos - SC. Horizontes,2013. Acesso em: 08 Out. 2016. 
PORTAL COCAL, 2016. Disponível em:

$<$,http://www.cocaldosul.sc.gov.br/noticias/index/ver/codNoticia/361323/codMapaItem/6245 \#.V-BAFDU1_T8>. Acesso em: 08 Out. 2016.

\section{PREFEITURA MUNICIPAL DE COCAL DO SUL. Documento de Histórico-Imigração}

Cocal do Sul. Secretaria de Educação: Cocal do Sul, 1993.

Disponível em: 〈http://www.bib.unesc.net/biblioteca/sumario/000055/00005568.pdf>

Acesso em: 25 Mai. 2016.

RABELO, Giani; VIRTUOSO Tatiane dos Santos. Escolas étnicas Italianas: Urussanga como principal centro ítalo-brasileiro catarinense no início do século XX. Criciúma: Acta Scientiarum. Education, 2015. Acesso em: 25 Set. 2016.

SANFELICE, José Luiz. História, Instituições Escolares e Gestores Educacionais.

Campinas: Revista HISTEDBR, 2006. Acesso em: 17 Out. 2016.

TOMASI, Julia Massucheti. Ritornando a lleorigini: a identidade italiana em Urussanga (SC) no final do século XX e início do XXI. Florianópolis: Revista Catarinense de História [on-line], 2012. Acesso em: 25 Out. 2016.

VENDRAMINI, Lucimary. Urussanga: da Escola Italiana á Escola Pública.

Florianópolis,2003. Acesso em: 24 Out. 2016.

ZAGO, Nadir. A entrevista e seu processo de construção: reflexões com base na experiência prática de pesquisa. In: ZAGO, Nadir; CARVALHO, Marília Pinto de; VILELA, Rita Amélia Teixeira. Itinerários de pesquisa: perspectivas qualitativas em sociologia da educação. $2^{\mathrm{a}}$. Ed. Rio de Janeiro: Lamparina 2011. 